\title{
Environmental Lead and Nickel Contamination of Tank Rainwater in Esperance, Western Australia: An Evaluation of the Cleaning Program
}

\author{
Jane S HEYWORTH ${ }^{1}$, Narelle MULLAN ${ }^{2}$ \\ ${ }^{1}$ School of Population Health, The University of Western Australia, Western Australia \\ ${ }^{2}$ Environmental Health Directorate, Department of Health, Western Australia \\ E-mail: jane.heyworth@uwa.edu.au \\ Received November 30, 2008; revised March 18, 2009; accepted March 19, 2009
}

\begin{abstract}
A significant number of birds in the port town of Esperance, Western Australia died in the summer of 2006/2007 and elevated lead levels were found in the kidneys, livers and brains of autopsied birds. These elevated lead levels alerted Government authorities to investigate the public health impacts of potential lead contamination in the community resulting from transport of lead carbonate from the Esperance Port. Water samples from domestic rainwater collection systems were collected to determine the extent of heavy metal contamination; $19 \%$ and $24 \%$ of tanks had lead and nickel levels above the Australian Drinking Water Guidelines. The aim of this study was to evaluate whether cleaning of rainwater tanks had reduced exposure to lead and nickel contamination in the community. Follow-up sampling of 176 tanks across Esperance indicated that that there had been reductions in both lead and nickel concentrations, but that the reduction has been greater for nickel concentrations. The reduction in nickel concentration was significantly associated with cleaning status, whereas this was not the case for lead. Proximity to the Esperance Port was an important determinant of lead concentration. Tank and roof characteristics did not significantly influence the follow-up lead concentrations. The results suggested that there was ongoing contamination of rainwater tanks from the environment.
\end{abstract}

Keywords: Lead Carbonate, Lead, Nickel, Rainwater Tanks, Environmental Exposure, Australia, Shipping Port

\section{Introduction}

In early 2007 residents and health authorities in Western Australian became concerned about the potential health impact of environmental lead exposure in the port town of Esperance, located on the Southeast coastline of Western Australia (WA). The population of the Shire of Esperance is approximately 13,000 and while the Shire covers an area of 42,450 square kms [1], the majority of the population lives in the Esperance town site. In April 2005 the Esperance Port Authority (EspPA) began shipping lead carbonate through the Esperance Port [2]. The lead was transported via rail from a mine site near Wiluna almost 900kms to the north. In December 2006 a significant number of bird deaths was reported and by the end of January 2007 up to 4000 birds were estimated to have had died [3]. High levels of lead were found in the livers, kidney and bones of dead birds. While lead was later determined unlikely to be the cause of the bird deaths, the elevated lead levels in these birds alerted Government authorities to investigate the potential public health impacts of lead contamination in the community. The EspPA put an immediate stop to any further shipments of lead carbonate from the Port [2].

The health effects of environmental lead exposure are well recognised with more recently attention focussed upon the health effects of lead exposure of $10 \mu \mathrm{g} / \mathrm{dL}$ or less in blood [4]. In 2005, the United States Centers of Disease Control and Prevention concluded that the weight of evidence supports an inverse association between blood lead levels of less than $10 \mu \mathrm{g} / \mathrm{dL}$ and cognitive function in children, but that it is as yet unclear re- 
garding the size of effect [5]. Currently the Australian standards for blood lead are under review, but the intervention level for community-wide prevention strategies set by both the World Health Organisation and the United States Centre of Disease Control and Prevention is $10 \mu \mathrm{g} / \mathrm{dL}$. The Western Australian Department of Health established a precautionary intervention level of $5 \mu \mathrm{g} / \mathrm{dL}$, in acknowledgment of the community concerns about chronic exposure to lower lead levels, particularly among children [2].

Between March and August 2007 blood testing was offered to all residents and 2,219 blood samples were taken. Thirty-three samples had lead levels of $10 \mu \mathrm{g} / \mathrm{dL}$ or more. Seven of the 404 children aged less than five years had blood lead levels of $10 \mu \mathrm{g} / \mathrm{dL}$ or more [6].

While lead exposure through air and dust were considered important exposure pathways, there was just one air monitoring station in Esperance. Hence it was not possible to characterise the extent and distribution of lead contamination across the town site using these data. Tank rainwater provided an alternative sampling framework for this purpose. A large proportion of households across the Esperance township collect rainwater from domestic roof catchments to supplement their mains water supply. The domestic roofs served as a catchment for airborne and dust-borne lead contamination that was the washed into the tanks. Thus water from rainwater tanks was potentially an important source of lead exposure.

As part of the investigation into the extent of lead contamination, the Department of Health, in conjunction with the Shire of Esperance, tested 1,539 rainwater tanks for heavy metals (Figure 1). The results of this tank rainwater testing showed that lead levels in rainwater exceeded the Australian Drinking Water Guidelines (ADWG) for lead $(0.01 \mathrm{mg} / \mathrm{L})$ in $285(19 \%)$ of tanks. Nickel levels in $369(24 \%)$ of rainwater tanks also exceeded the ADWG $(0.02 \mathrm{mg} / \mathrm{L})[7,8]$.

Subsequently, the EspPA coordinated the cleaning of rainwater tanks and gutter systems for 1) residences identified with high lead levels in their tank rainwater sample and 2) tanks in the area identified by the Department of Health as more likely to have been impacted by lead pollution. The cleaning process involved: draining water from the tanks and pressure cleaning of the internal sides and bottom of the tank; vacuuming sludge residues

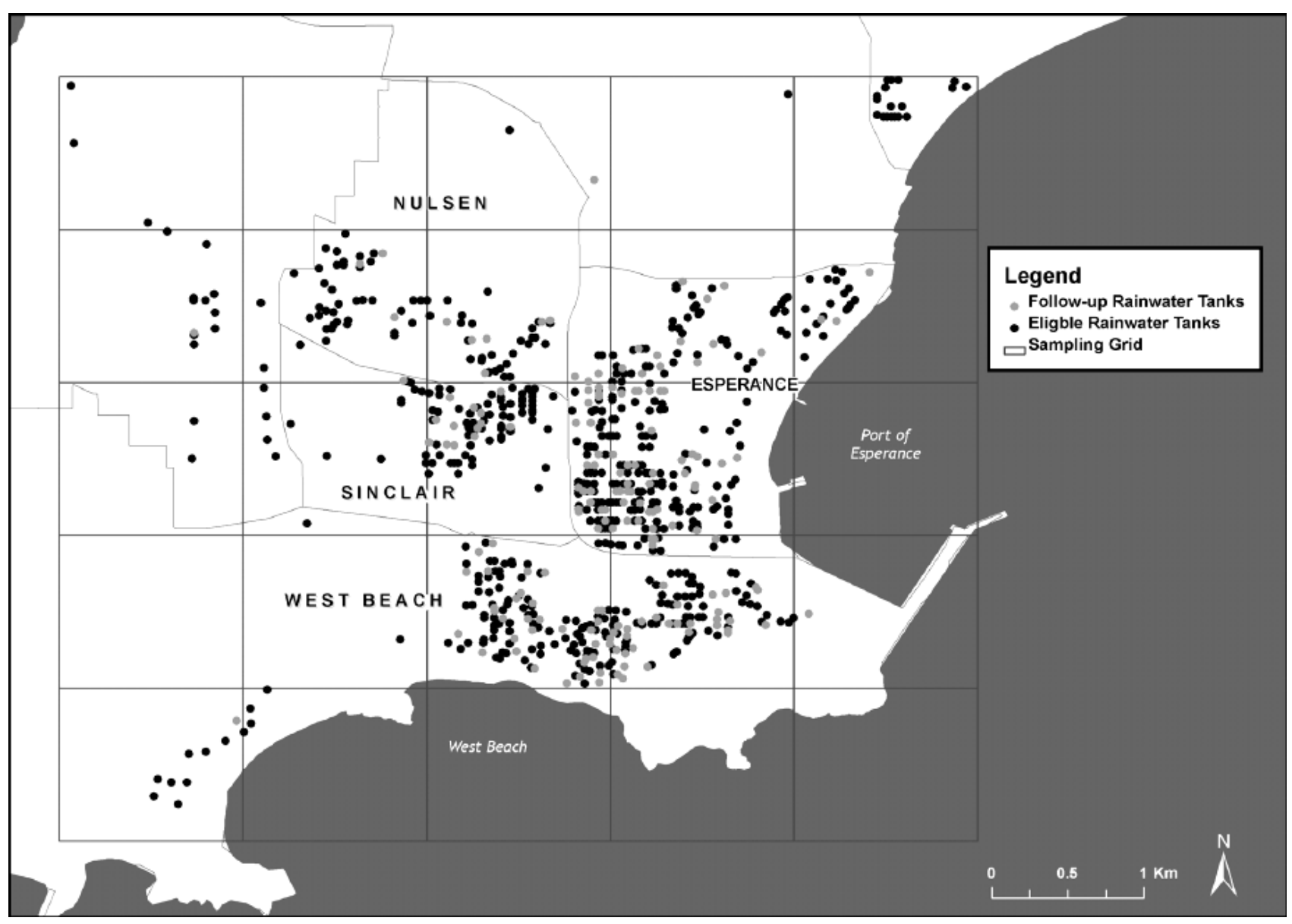

Figure 1. Location of rainwater tanks that were eligible for re-sampling, Esperance, October 2007. 
out of the tank; and pressure cleaning gutters and the bottom part of roof area.

A total 423 tanks were cleaned as a part of this follow up program.

This paper reports on the follow up sampling undertaken to evaluate the rainwater tank cleaning program. The aims were to determine whether cleaning of rainwater tanks had been successful in reducing the lead and nickel levels to below the ADWG for lead $(0.01 \mathrm{mg} / \mathrm{L})$ and nickel $(0.02 \mathrm{mg} / \mathrm{L})$ and, if the levels remained high, what factors contributed to those elevated levels.

\section{Methods}

\subsection{Study Population}

A subset of rainwater tanks in Esperance were selected from initial population of rainwater tanks that weretested as part of the ongoing investigation of lead contamination in Esperance (Figure 1). Tanks in the suburb of Castletown (outside the grid area of Figure 1) were excluded in this follow-up investigation because this area was at low risk of lead contamination. The final study area contained 806 rainwater tanks that were eligible for retesting.

The study area was stratified by a $1 \mathrm{~km}$ square grid, resulting in 25 cells (Figure 1). A random sample of 236 tanks was selected from across the grids, proportional to the number of rainwater tanks initially tested in each grid. Consent to sample tanks as well as access to the property was gained for 179 tanks out of the 236 tanks.

\subsection{Water Sampling and Analysis}

Baseline water samples were collected by the Department of Health and the Shire of Esperance between April and June 2007. Follow-up samples were collected after the period during which rainwater tanks had been cleaned. The follow-up samples were collected by the Department of Health and the Shire of Esperance from 15 to 29 October 2007 and taken from tanks that were cleaned and those that were not.

All samples were analysed for lead and nickel concentrations by the NATA accredited Chemistry Centre (Western Australia) using the method, 3120B Inductively Coupled Plasma Method from the Standard Method for the Examination of Water and Wastewater [9].

\subsection{Rainwater Tank Data}

When the baseline samples were collected, data regarding the tank and catchment characteristics were obtained by the officer taking the sample. For 143 households, the resident was also surveyed to obtain additional information on: location; roof catchment material-tile, asbestos cement, Colourbond, zincalume; condition of roof catchment; gutters material, tank material-zincalume, galvanised iron, plastic, concrete, other; condition of the rainwater tank; presence of first flush diverter; opening on tank roof; other possible sources of lead including lead flashing, gutter type, etc.; date on which the tank was last cleaned, if not cleaned by EspPA.

Ninety-seven tanks were cleaned by EspPA between May and August, 2007. In the survey of residents $(n=$ 143), an additional 29 tanks were reported to have been cleaned privately between March and September of 2007. The time between cleaning and the second sample ranged from 6 to 33 weeks, with a mean of 19 weeks.

\subsection{Statistical Analysis}

Descriptive statistics for lead and nickel concentrations and changes over time were determined. Medians are presented because the lead and nickel concentrations were skewed towards zero. These results were compared with the ADWG, that is $0.01 \mathrm{mg} / \mathrm{L}$ for lead and $0.02 \mathrm{mg} / \mathrm{L}$ for nickel.

Results were mapped using the ESRI ArcMap software. Smooth grids of the testing results were achieved with ESRI Spatial Analyst, using the kernel density tool that transforms point data into a smoothed grid via a moving window technique [10].

Tank and roof characteristics, cleaning status and distance from the Port were compared across lead and nickel samples above and below the ADWG. The relationships between the lead and/or nickel concentrations at follow-up and cleaning status, distance from the Port, rainwater tank and roof catchment characteristics and adjusting for baseline lead or nickel concentration, were modelled using linear regression. The natural logarithms of the lead and nickel levels were used in all models because these data were skewed to the left. The dependent variable was the follow-up lead reading, with the first metal reading included in the model. Distance was measured in kilometres and as a continuous variable. Cleaning was modelled as a dichotomous variable.

The statistical analysis was conducted using STATA 9 (Texas) statistical packages [11].

\section{Results}

\subsection{Descriptive Analysis of Lead and Nickel Concentrations}

Among the 236 tanks randomly selected for re-sampling, 176 households agreed to have their rainwater tanks re-sampled. The median concentrations of both lead and nickel decreased between baseline and follow-up samples (Table 1). At baseline the median concentrations for 
lead was at the ADWG and for nickel it was above the ADWG. At follow up, the median level had reduced by $55 \%$ for lead and $85 \%$ for nickel.

Figures 2(a) and (b) present smoothed maps of lead concentrations in the study area at baseline and follow-up. Figures 3(a) and b are smoothed maps of nickel concentrations in the study area as at baseline and follow-up.

\subsection{Comparisons by Cleaning Status}

Data on whether the rainwater tank had been cleaned were available for 161 tanks. There were reductions in median lead and nickel concentrations in both tanks that were cleaned and those not cleaned (Table 1). The reduction was greatest for nickel in cleaned tanks. The percentage reduction in median nickel concentrations was $88 \%$, whereas for those tanks not cleaned the reduction in nickel concentration was $63 \%$. For lead there was little difference in the reduction between the cleaned tanks and not cleaned tanks; the reductions in the median concentrations were $58 \%$ and $60 \%$ respectively. An analysis of variance indicated that the difference in the median concentration between follow-up

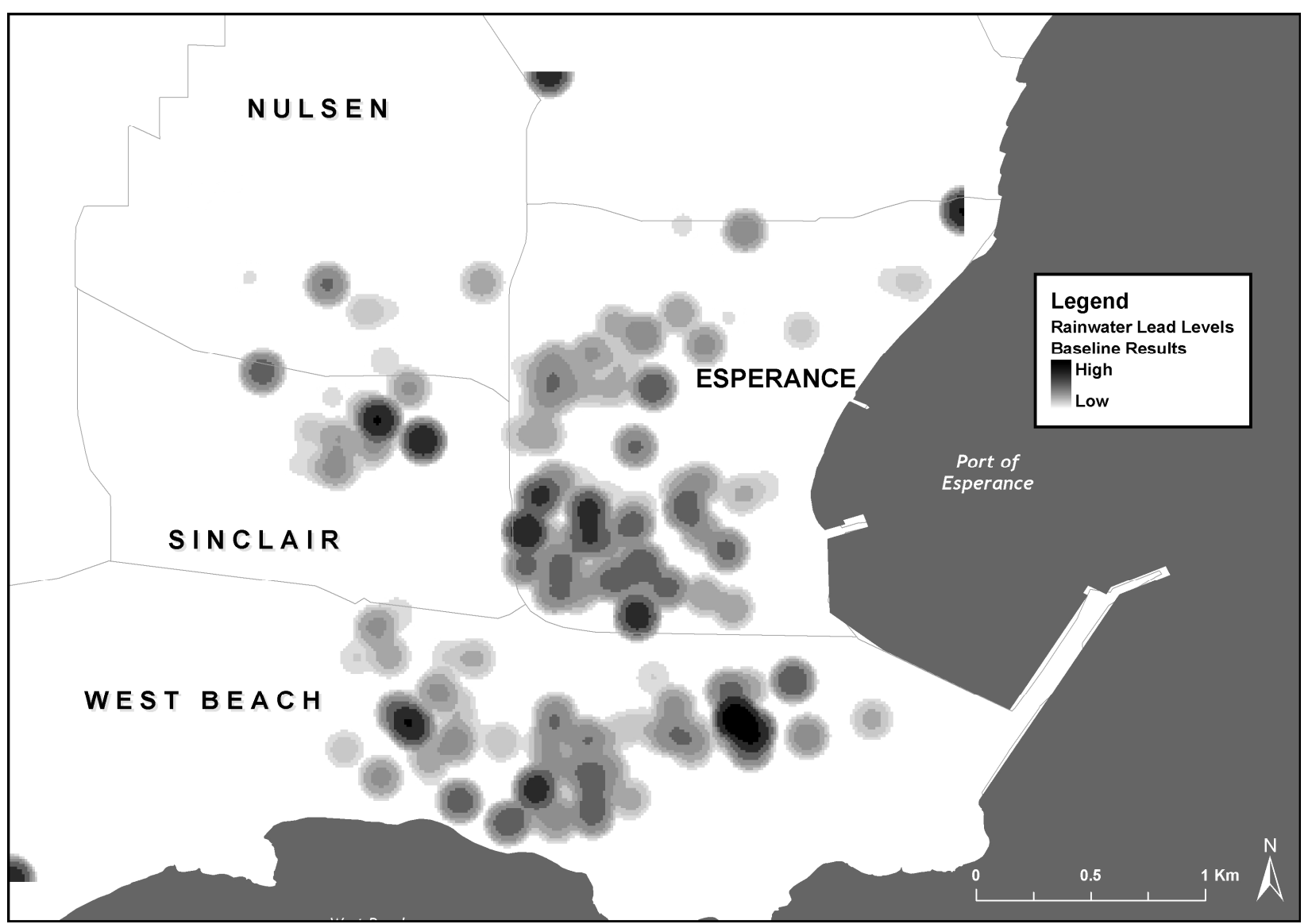

Figure 2(a). Spatial distribution of lead levels in rainwater tanks at baseline, esperance March-June 2007.

Table 1. Lead and Nickel concentrations $(\mathrm{mg} / \mathrm{L})$ in tank rainwater at baseline and follow-up for all tanks $(\mathrm{n}=176)$ and by cleaning status, Esperance 2007 (n=161)1.

\begin{tabular}{lcccccc}
\hline & \multicolumn{2}{c}{ All Tanks $(\mathrm{n}=176)$} & \multicolumn{2}{c}{ Tanks cleaned by EspPA ${ }^{2}$ or privately $(\mathrm{n}=125)$} & \multicolumn{2}{c}{ Tanks not cleaned $(\mathrm{n}=36)$} \\
\hline Lead & Median & Range & Median & Range & Median & Range \\
Baseline & 0.010 & $0.001-0.160$ & 0.012 & $0.001-0.160$ & 0.005 & $0.001-0.100$ \\
Follow up & 0.004 & $0.0004-0.100$ & 0.005 & $0.001-0.110$ & 0.002 & $0.000-0.038$ \\
Nickel & & & & & \\
Baseline & 0.027 & $0.001-0.700$ & 0.032 & $0.001-0.680$ & 0.008 & $0.002-0.110$ \\
Follow up & 0.003 & $0.000-0.110$ & 0.004 & $0.002-0.700$ & 0.003 & $0.001-0.110$ \\
\hline
\end{tabular}

1. cleaning status not known for 15 tanks; 2. EspPA- Esperance Port Authority. 


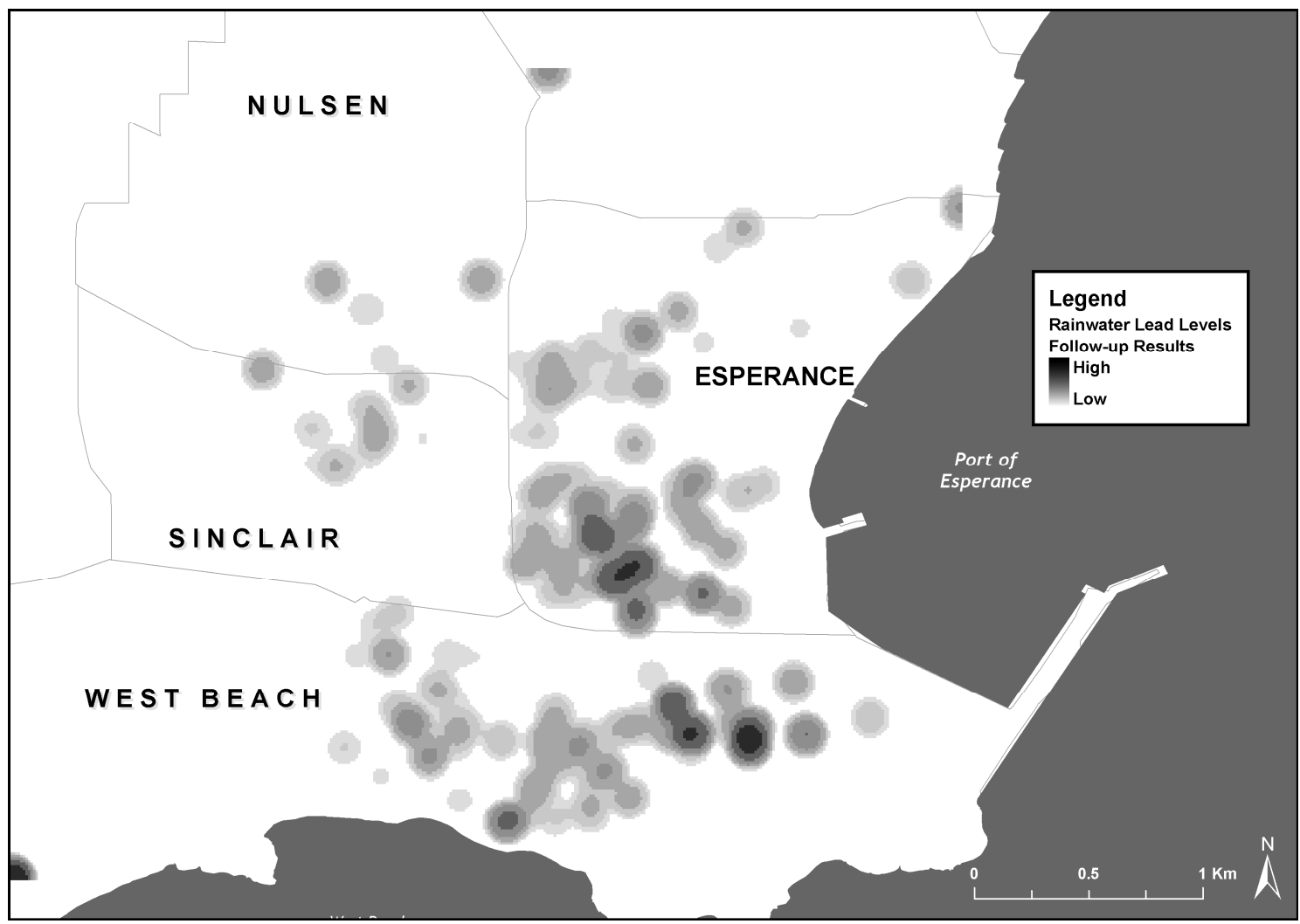

Figure 2(b). Spatial distribution of lead levels in rainwater tanks at follow-up, Esperance, October 2007.

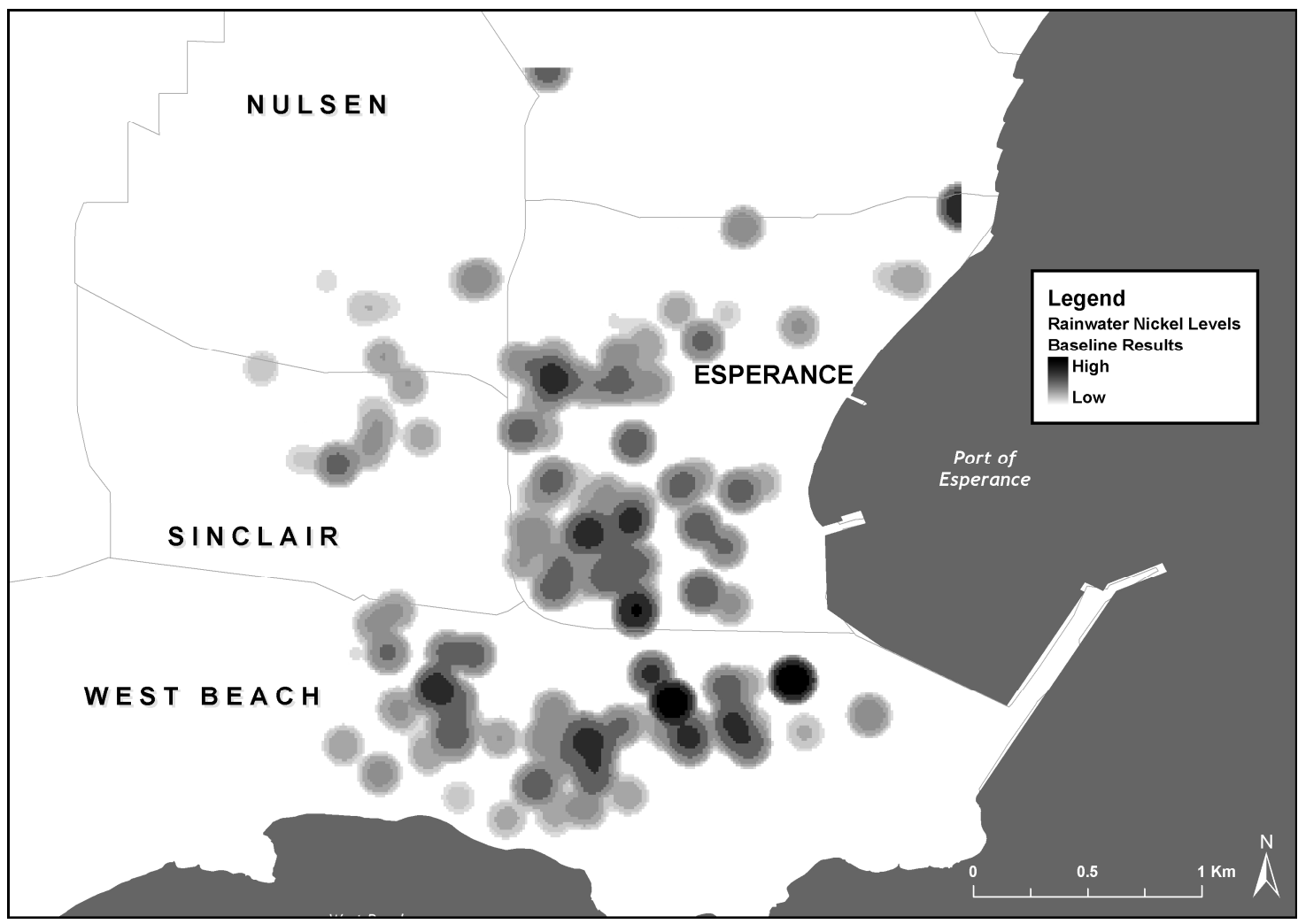

Figure 3(a). Spatial distribution of nickel levels in rainwater tanks at baseline, Esperance, March-June, 2007. 


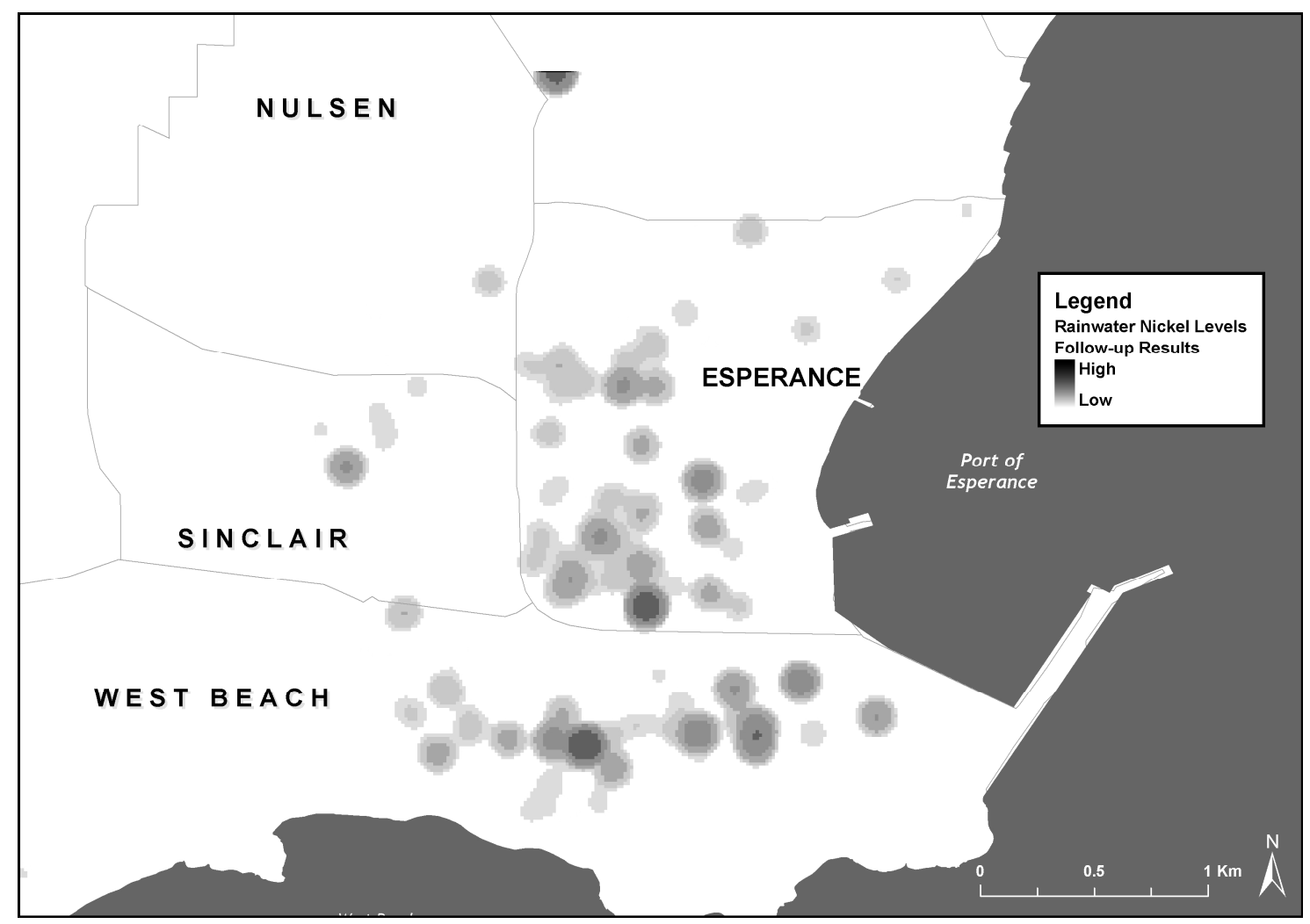

Figure 3(b). Spatial distribution of nickel levels in rainwater tanks at follow-up, Esperance, October 2007.

and baseline was not significantly associated with cleaning status for lead $(\mathrm{p}=0.228)$ but was for nickel $(\mathrm{p}<0.001)$.

For lead, the proportion above the ADWG reduced by $61 \%$ in the cleaned group compared with $33 \%$ in the not cleaned group. For nickel, the proportion above the ADWG reduced by $92 \%$ compared with $50 \%$ in the not cleaned group.

When the cleaned tanks were stratified by date of cleaning, that is the period, March to June, compared with July onwards, the follow up medians were the same.

\subsection{Characteristics of Tanks Sampled}

The characteristics of the tanks and their roof and gutter catchment areas were available for maximum of 143 tanks. Tanks were predominantly made of zincalume $(38 \%)$ and plastic (32\%) with some colourbond (21\%) and fibreglass tanks (8\%). There were no concrete tanks. Nearly all tanks (96\%) were reported to be in good condition. Five per cent of tanks had a first flush diverter, and most did not have an opening on the tank roof. Over half the tanks $(55 \%)$ had a screened inlet.

The most common roof material was Colourbond, followed by tile. For gutters Colourbond was the most common material. Of the 132 tanks for which the roof condition was noted, $86 \%$ were in a good condition. For gutters, $44 \%$ of households cleaned their gutters at least annually, whereas $56 \%$ never or irregularly cleaned gutters.

Comparisons were made of lead and nickel concentrations at follow-up sampling by tank or roof catchment characteristics (Table 2). Opening in the tank roof was statistically significantly associated with higher nickel concentrations. While there were no significant differences in the distribution of metal concentration by tank and catchment characteristics, there was a tendency for higher lead levels to be associated with plastic tanks, tile or asbestos roofs and an opening in the tank roof. For nickel, there was a tendency for higher concentrations for colourbond roofs and gutters.

\subsection{Lead and Nickel Concentrations at Follow up by Distance from the Port}

The distributions of lead concentrations for all 176 samples at follow up by distance from the Esperance Port are shown in Table 3. Water samples that were above the lead ADWG tended to be from tanks closer to the Port; $69.5 \%$ of samples were within $1.5 \mathrm{kms}$ of the Port compared with $54 \%$ of samples below the ADWG for lead $(p=0.025)$.

Just 13 samples were at or above the ADWG for nickel at follow-up; six of these were located within 1 $\mathrm{km}$ of the Port, five between $1.01 \mathrm{~km}$ and $1.5 \mathrm{~km}$, and two were more than $2 \mathrm{~km}$ from the Port. 
Table 2. Cross-tabulation of tank and catchment characteristics by proportion of samples above and below $0.01 \mathrm{mg} / \mathrm{L}$ lead and above and below $0.02 \mathrm{mg} / \mathrm{L}$ nickel at follow up sampling (n=143).

\begin{tabular}{|c|c|c|c|c|c|c|c|c|c|}
\hline \multirow{2}{*}{\multicolumn{2}{|c|}{ Tank and roof characteristics ${ }^{1}$}} & \multicolumn{4}{|c|}{ Lead concentration } & \multicolumn{4}{|c|}{ Nickel concentration } \\
\hline & & \multicolumn{2}{|c|}{$<0.01 \mathrm{mg} / \mathrm{L}$} & \multicolumn{2}{|c|}{$<0.01 \mathrm{mg} / \mathrm{L}$} & \multicolumn{2}{|c|}{$<0.02 \mathrm{mg} / \mathrm{L}$} & \multicolumn{2}{|c|}{$\geq 0.02 \mathrm{mg} / \mathrm{L}$} \\
\hline & & $\mathrm{n}$ & $\%$ & $\mathrm{n}$ & $\%$ & $\mathrm{n}$ & $\%$ & $\mathrm{n}$ & $\%$ \\
\hline \multirow{3}{*}{ Tank material } & Zincalume & 43 & 39.1 & 10 & 33.3 & 48 & 37.8 & 5 & 38.5 \\
\hline & Colourbond & 23 & 20.9 & 7 & 23.3 & 27 & 21.2 & 3 & 23.1 \\
\hline & Plastic & 34 & 30.9 & 11 & 36.7 & 41 & 32.3 & 4 & 30.8 \\
\hline \multirow{5}{*}{ Roof material } & Fibreglass & 10 & 9.1 & 2 & 6.7 & 11 & 8.7 & 1 & 7.7 \\
\hline & Zincalume & 19 & 17.3 & 6 & 20.0 & 23 & 18.1 & 2 & 15.4 \\
\hline & Colourbond & 51 & 46.4 & 10 & 33.3 & 53 & 41.7 & 8 & 61.5 \\
\hline & Asbestos cement & 6 & 5.4 & 3 & 10.0 & 7 & 5.5 & 2 & 15.4 \\
\hline & Tile & 34 & 30.9 & 11 & 36.7 & 44 & 34.7 & 1 & 7.7 \\
\hline \multirow{4}{*}{ Gutter material } & Zincalume & 32 & 28.3 & 9 & 30.0 & 39 & 30.0 & 2 & 15.4 \\
\hline & Colourbond & 54 & 47.4 & 16 & 53.3 & 62 & 47.7 & 8 & 61.5 \\
\hline & Plastic & 5 & 4.4 & 1 & 3.3 & 6 & 4.6 & 0 & 0.0 \\
\hline & Other & 22 & 19.5 & 4 & 13.3 & 23 & 17.7 & 3 & 23.1 \\
\hline \multirow{2}{*}{$\begin{array}{l}\text { Opening in tank } \\
\text { roof }^{2}\end{array}$} & No & 94 & 83.2 & 24 & 80.0 & 110 & 84.6 & 8 & 61.5 \\
\hline & Yes & 19 & 16.8 & 6 & 20.0 & 50 & 15.4 & 5 & 38.5 \\
\hline \multirow[t]{2}{*}{ Roof condition } & Poor/average & 17 & 16.3 & 1 & 3.6 & 15 & 12.5 & 3 & 25.0 \\
\hline & Good & 87 & 83.7 & 27 & 96.4 & 105 & 87.5 & 9 & 75.0 \\
\hline
\end{tabular}

1. Total may not add to 143 due to missing data; 2 . Significant difference for nickel $\mathrm{p}=0.037$.

Table 3. Lead concentrations by distance from the Esperance port $(n=176)$.

\begin{tabular}{|c|c|c|c|c|c|}
\hline \multirow[t]{3}{*}{ Distance from port } & & \multicolumn{4}{|c|}{ Lead concentration at follow-up } \\
\hline & \multirow[b]{2}{*}{ Total } & \multicolumn{2}{|c|}{$<0.01 \mathrm{mg} / \mathrm{L}$} & \multicolumn{2}{|c|}{$\geq 0.01 \mathrm{mg} / \mathrm{L}$} \\
\hline & & $\mathrm{n}$ & $\%$ & $\mathrm{n}$ & $\%$ \\
\hline $0-1.00 \mathrm{~km}$ & 26 & 15 & 10.7 & 11 & 30.6 \\
\hline $1.01-1.50 \mathrm{~km}$ & 75 & 61 & 43.6 & 14 & 38.9 \\
\hline $1.51-2.00 \mathrm{~km}$ & 44 & 38 & 27.1 & 6 & 16.7 \\
\hline More than $2.00 \mathrm{~km}$ & 31 & 26 & 18.6 & 5 & 13.9 \\
\hline
\end{tabular}

Table 4. Linear Regression Models: Effect of cleaning, distance from Port and baseline concentration on follow up concentration of (1) lead and (2) nickel, (n=161).

\begin{tabular}{|c|c|c|c|c|c|}
\hline & Coefficient & t-statistic & \multicolumn{2}{|c|}{$95 \%$ Confidence Interval } & $\mathrm{P}$-value \\
\hline Constant & -2.825 & -7.35 & & & \\
\hline LnPb-Baseline & 0.437 & 7.39 & 0.320 & 0.554 & $<0.001$ \\
\hline Cleaned versus not cleaned & 0.106 & 0.62 & -0.232 & 0.444 & 0.537 \\
\hline Distance in kilometres & -0.416 & -3.45 & -0.654 & -0.177 & 0.001 \\
\hline \multicolumn{6}{|l|}{ Model for nickel } \\
\hline Constant & -3.049 & -9.16 & & & \\
\hline LnNi-Baseline & 0.288 & 4.30 & 0.156 & 0.421 & $<0.001$ \\
\hline Cleaned versus not cleaned & -0.666 & -3.72 & -1.020 & -0.312 & $<0.001$ \\
\hline Distance in kilometres & -0.569 & -4.09 & -0.844 & -0.294 & $<0.001$ \\
\hline
\end{tabular}




\subsection{Linear Regression Models}

Distance from the Port was significantly related to the second lead reading. As distance from the Port increases the lead concentration decreases. Cleaning status had no significant influence on the second lead reading. For nickel, both cleaning status and distance from the Port led to a significant reduction in the second nickel concentration.

None of the tank and catchment characteristics were associated with lead or nickel concentrations when included in the model (data not presented).

\section{Discussion}

These data indicate that that there have been reductions in both lead and nickel concentrations, but that the reduction has been greater for nickel concentrations. The reduction in nickel concentration was significantly associated with cleaning status, whereas this was not the case for lead. While the lead levels in rainwater tanks have reduced, the reduction is less with increasing proximity to the Port. Tank and roof characteristics did not significantly influence the follow-up lead concentrations.

The effect of distance from the Port on follow-up lead levels may have reflected one of four possibilities. First, the Port may have been a source of ongoing lead contamination. While lead carbonate was no longer handled at the Esperance Port, the buildings, railway lines and grounds within the Port that surrounded areas where the lead carbonate was unloaded from kibbles and loaded onto ships, may have been still contaminated with lead. This lead could then have been re-entrained into the air and contaminated rainwater tanks closer to the Port. Second, trees and shrubs and soil in the local environment may still have been contaminated with lead and this lead could have been re-entrained by wind into the air and deposited on roof catchments. Investigations in Port Pirie, where a large lead-zinc smelter exists, have illustrated the persistence of higher levels of contamination nearest the smelter. Maynard el al. (2003) in a review of the Lead Decontamination Program, concluded that re-entrainment from the smelter and environs was a more important contributor to air borne lead levels than re- entrainment from contaminated areas in the city.

The winds most likely to pick up contamination from the Port and the surrounding areas and then transport this across the town site were from the North through to the South-East. During the months between the baseline and follow up samples, winds followed either an autumn or winter pattern. During autumn the prevailing winds in the morning are from the North/ North-West and NorthEast, and in the afternoon they are from the South-East and South. In winter period the prevailing winds were from the North-West/ North and West for both morning and afternoon (http://www.bom.gov.au/climate/averages /wind/selection_map.shtml). Hence it is possible that rainwater tanks have been re-contaminated by lead in the environment.

Third, the cleaning protocol for rainwater required only that the bottom part of the roof (one metre) be cleaned. Cleaning of the roof catchment may not have adequately removed lead from this environment, with those closest to the Port having the higher levels of lead deposition in the past. With time this contamination would have been washed into the rainwater tanks.

Last, it may have been a combination of these and as a result a range of responses may be required. While children living closest to or downwind of the Port Pirie smelter have continued to have the highest blood lead levels, there is evidence that some interventions have been successful reducing blood lead levels in Port Pirie children [12]. These have included avoidance of tank rainwater, reduction of airborne smelter emissions, relocation of children to lower exposure suburbs, worker hygiene improvements, community education and house decontamination. While not all are relevant to Esperance, where the exposure is has a short history, is lower and no longer ongoing, a broader based intervention is required.

There are a number of reasons as to why nickel may not have re-contaminated tanks and for levels to have reduced to a greater extent than lead. Nickel has been handled at the Port for about 30 years and any cleaning of the Port environment would have removed deposits that have built up over a long period of time. The concentrate is between $8 \%-15 \%$ nickel, whereas for lead, the concentrate is in the order of $65 \%$ lead. There has been a number of engineering upgrades at the Port to reduce the potential for nickel dust. The EspPA has specified the minimum moisture content and $\mathrm{pH}$ of nickel arriving at the Port and maintained the moisture content during storage in sheds at the wharf. There has been a presence of Department of Environment and Conservation officers monitoring nickel concentrate loaded onto ships.

The extensive use of domestic rainwater collection systems across Esperance allowed us to obtain a comprehensive picture of the extent and distribution of lead and nickel contamination across the town. This would not otherwise have been obtainable in a small community such as Esperance. However, an important limitation of this study was the extent of missing data. Data were collected as part of an ongoing investigation, rather than for research purposes. While some residents had given their consent for sample collection, they were not able to be present at the time of sampling. Hence there are missing data on tank and roof characteristics as well as tank cleaning status. In other cases where surveys were administered, it was sometimes difficult for the resident, who may have been a tenant, to know or recall information on tank and roof characteristics. 
In conclusion, the most important factor influencing the follow-up lead readings was the distance from the Port. As the distance from the Port increased, the follow-up lead concentration decreased. On the other hand, whether a tank was cleaned had no apparent effect on the follow-up lead concentration. These findings suggest that there may be ongoing contamination of rainwater tanks from the environment. The pattern of continuing high lead levels may be a result of ongoing contamination arising from the Port environment, the re-mobilisation of existing lead contamination of the environment, the difficulties in removing residual lead from the roof catchment areas or a combination of these. Nickel levels have been reduced substantially as a result of the rainwater tank cleaning program.

As a result of these findings it was recommended that people in Esperance continue to be advised not to drink rainwater. In addition, it was recommended that there be further investigation of lead levels in the Port environs, the surrounding residential areas and roofs to identify and address any environmental sources of lead.

\section{References}

[1] Shire of Esperance, cited September 4, 2008, http://www.esperance.wa.gov.au/.

[2] Education and Health Standing Committee, Legislative Assembly, "Response of the Western Australian Government to the Western Australian in relation to the cause and extent of lead pollution in the Esperance Area," Perth: Government of Western Australia, 2007.

[3] Department of Environment and Conservation, "Update \#2: Esperance bird deaths. 2007," [cited 4 September
2008]; 13 March 2007: [Available from: http://portal. environment.wa.gov.au/pls/portal/docs/PAGE/DOE ADMIN/MEDIA_REPOSITORY/TAB $108326 /$ TAB 6428377/BIRD_UPDATE23032007.PDF.

[4] T. A. Jusko, C. R. Henderson, B. P. Lanphear, et al., "Blood lead concentrations $<10 \mathrm{microg} / \mathrm{dL}$ and child intelligence at 6 years of age," Environmental Health Perspectives, Vol. 116, pp. 243-248, February 2008.

[5] Centers for Disease Control and Prevention, "Preventing lead poisoning in young children," Atlanta: CDC, 2005.

[6] Education and Health Standing Committee Legislative Assembly, "Inquiry into the cause and extent of lead pollution in the Esperance Area," in: Printer G, editor: State Law Publisher, Western Australia, 2007.

[7] Environmental Health Directorate, DoH, Western Australia, "Rainwater tank sample results. 2007," cited September 4, 2008, http://www.health.wa.gov.au/envirohealth/ home/docs/RWT_Summary_Stats.pdf.

[8] NHMRC, NRMMC, "Australian drinking water guidelines 6," Canberra: National Health and Medical Research Council and Natural Resource Managment Ministerial Council, 2004.

[9] American Public Health Association, "Standard method for the examination of water and wastewater, 20th Edition, Method 3120B inductively coupled plasma method," 1998.

[10] ESRI, "Using ArcGIS spatial analyst: ArcGIS9," Redlands: ESRI Press, 2004

[11] StataCorp, "Stata statistical software: Release 9," College Station, TX: StataCorp LP, 2005.

[12] E. Maynard, R. Thomas, D. Simon, et al. "An evaluation of recent blood lead levels in Port Pirie, South Australia," Science of The Total Environment, Vol. 15, No. 303, pp. 25-33, February 2003. 